\title{
P2 purinoceptors and the kidney
}

\author{
R. J. Unwin • D. G. Shirley
}

Published online: 21 March 2009

(C) Springer Science + Business Media B.V. 2009

Research into the humoral control of kidney function has a long tradition, but the idea that local, intrarenally produced factors (as distinct from circulating hormones) may play an important autocrine/paracrine regulatory role is a more recent concept. Putative intrarenal systems include locally generated angiotensin II, endothelins, eicosanoids and nitric oxide; as yet, however, no well-defined regulatory system has been firmly established. Recent promising candidates for this form of control are the adenosine-sensitive P1 and nucleotidesensitive $\mathrm{P} 2$ purinoceptor systems. For the $\mathrm{P} 2$ receptor system in particular, all the necessary components (ATP, degradative enzymes and a range of $\mathrm{P} 2$ receptors) have been identified within the kidney, and the last 10 years have seen an explosion of interest in the role of this system in both health and disease.

This Special Issue brings together, for the first time, the key aspects of the renal P2 receptor system, reviewed by leading workers in the field. The articles cover the sources and release of ATP; the effects of ATP on the renal microcirculation; its signalling function at the interface of the tubule and glomerulus; its role in tubular transport, including sodium and water; the enzymes that control the breakdown of ATP (and the active products that have differing receptor specificity, introducing yet another layer of complexity to this system); and, finally, what may happen when the system goes awry.

Although there is still much to learn about the precise role of the renal P2 receptor system, there is now wider acceptance that it does have a real and important function. This timely collection of well-informed and insightful articles summarises where we are now and signals the future directions we should take.

R. J. Unwin $(\bowtie) \cdot$ D. G. Shirley $(\bowtie)$

Centre for Nephrology, Division of Medicine,

University College London Medical School,

Royal Free Campus, Rowland Hill Street,

London, NW3 2PF, UK

e-mail: r.unwin@ucl.ac.uk

e-mail: david.shirley@ucl.ac.uk 